\title{
Lumbar Puncture: It Is Time to Change the Needle
}

\author{
Ronit Lavi ${ }^{\mathrm{a}} \quad$ J.M. Rowe ${ }^{\mathrm{b}} \quad$ Irit Avivi $^{\mathrm{b}}$ \\ ${ }^{a}$ Department of Anesthesia and Perioperative Medicine, London Health Sciences Centre, University Hospital \\ London, London, Ont., Canada; ${ }^{b}$ Department of Hematology, Rambam Medical Center, Haifa, Israel
}

\section{Key Words}

Lumbar puncture - Post-lumbar puncture headache Needle

\begin{abstract}
Lumbar puncture is a frequent procedure performed by physicians from several disciplines to help establish a diagnosis and treatment for several diseases. Post-lumbar puncture headache (PLPH) is a frequent complication that typically lasts for a couple of days and can be severe enough to immobilize the patient and to require therapy. There are several risk factors identified, pain characteristics, and characteristic findings on spinal and head magnetic resonance imaging. There are several procedural factors that have been identified to be of consequence in attenuating the PLPH incidence, specifically the needle type and size used for this procedure. Once PLPH occurs, the clinician should treat it conservatively with bed rest, analgesics and increased fluids intake, especially caffeine-containing beverages, as it can dramatically affect the patient's wellness. If the pain is severe and disabling and does not respond to conservative treatment, a blood patch should be considered at least 24-48 $\mathrm{h}$ following the LP. Epidural blood patch is a safe and rapidly effective treatment in experienced hands. Furthermore, patients who developed PLPH should be advised to contact the
\end{abstract}

medical staff in case of changes in the characteristics of headaches. When a patient who was diagnosed with PLPH has a change in the pain character, or additional neurological manifestations appear, an urgent brain CT/head MRI should be performed to exclude rarer life-threatening intracranial complications.

Copyright $\odot 2010$ S. Karger AG, Basel

\section{Introduction}

Lumbar puncture (LP) is performed by neurologists on a daily basis. The most prevalent complication of LP is post-lumbar puncture headache (PLPH), the frequency of which can be markedly reduced by using smaller atraumatic needles. The current review summarizes the published data and provides updated information as well as practical guidelines for LP performing and treatment of PLPH.

\section{PLPH Characteristics}

LP is a common procedure performed by physicians from several disciplines. The technique is aimed at collection of cerebral spinal fluid (CSF) for analysis, mea-

\section{KARGER}

Fax +4161306 1234 E-Mail karger@karger.ch www.karger.com
(C) 2010 S. Karger AG, Basel $0014-3022 / 10 / 0642-0108 \$ 26.00 / 0$

Accessible online at:

www.karger.com/ene
Ronit Lavi, Department of Anesthesia and Perioperative Medicine

London Health Sciences Centre, University Hospital and St. Joseph's Health Care

University of Western Ontario, Room C3-104, 339 Windermere Road

London, ON N6A 5A5 (Canada)

Tel. +1 519663 2259, Fax +1 519663 2957, E-Mail Ronit.Lavi@lhsc.on.ca 
surement of opening pressures, and injection of intrathecal chemotherapy, as well as local anesthetics and analgesics for applying spinal anesthesia.

PLPH is a common sequel of LP, occurring in about $40 \%$ of patients $(<1-70 \%)$ [1]. The onset of the headache might vary from immediately after the dural puncture to usually $24-48 \mathrm{~h}$ and up to 12 days following the LP. PLPH typically lasts for 1 or 2 days and is frequently severe enough to immobilize the patient and require therapy. Rarely, PLPH can persist for 2 weeks or longer. Considerable and prolonged PLPH persisting for months or even a year or more, was previously reported [2]. The pain is dull or throbbing in nature and varies in its intensity from mild to severe and disabling. The headache is usually frontal, occipital or diffuse, and radiates to the neck and shoulders. The temporal, vertex and nuchal areas are reported less commonly as the site of discomfort, although neck stiffness may be observed. PLPH tends to exacerbate by changing position, especially from lying to upright posture and by head movement, e.g. head-shaking, coughing, straining, sneezing, and jugular compression, and to be relieved when lying flat on the back with the head centered for at least $15 \mathrm{~min}$.

Other symptoms that may be associated with PLPH include nausea, vomiting, hearing loss, tinnitus, vertigo, dizziness, diplopia, cranial nerve palsies and paresthesia of the scalp, and upper or lower limb pain. When the PLPH character changes and other neurologic sequels appear, the clinician must suspect the development of subdural hematoma or sinus vein thrombosis and perform an urgent MRI to exclude these diagnoses [3-8].

\section{Pathophysiology of PLPH}

In a normal human, production of CSF amounts to $450-500 \mathrm{ml} /$ day $(0.3 \mathrm{ml} / \mathrm{min})$. The normal CSF volume is $150 \mathrm{ml}$ and the body generates its entire CSF volume 3 times a day. PLPH can be stopped by blocking the leakage of CSF, since the tear created in the dura may cause a continuous CSF leakage through the dural puncture site into the epidural and paravertebral spaces faster than its production rate, resulting in a reduction of the CSF pressure. This intracranial hypotension causes subsequent gravitydependent downward sagging of the brain, inducing pain by traction of the anchoring sagittal sinus and its tributary veins and pressure on the tentorium and the large cerebral arteries [9]. When the patient stands up, or suddenly changes position, there is a sudden reduction of CSF volume below the cisterna magna and a downward movement of brain tissue with displacement and stretching of pain-sensitive structures, such as meninges and vessels, which, in turn, causes a traction headache. The intracranial pressure decreases and intracranial venous distension increases, worsening the headache.

A combination of low CSF pressure and resultant cerebral vasodilatation might have an impact on the reaction to the stretching of vessels. Venous dilatation is known to partially compensate for the loss of intracranial volume and may be responsible for the sensation of pressure that is experienced with PLPH.

The trigeminal, glossopharyngeal and vagus nerves are thought to be involved in this process. Vagal traction may stimulate chemoreceptors in the medulla to induce nausea. Traction on the abducens and trochlear nerves can lead to ocular muscle paralysis, with subsequent strabismus and double vision $[10,11]$. Hearing loss has also been reported, due to a low CSF pressure transmitted to the inner ear via the cochlear aqueduct. This decrement in hearing is usually fully reversible once normal subarachnoid pressure is restored, but permanent hearing loss has been reported $[12,13]$. Neck pain may result from tension on cervical nerves $\mathrm{C}_{1-3}$ and may develop into a myofascial-like pain [14]. When supine, equalization of intracranial cisternal and lumbar CSF pressures takes place, the CSF leakage decreases, there is less pressure on the meninges and cerebral arteries; thus, no expansion of the venous system occurs, and the headache improves.

\section{Spinal and Head Magnetic Resonance Imaging}

There are several descriptions of head and spinal MRI findings in patients suffering from severe and prolonged PLPH. The most common findings in head MRI are diffuse pachymeningeal enhancement and decrease in the size of the ventricles. Other findings described include a descent of the cerebellar tonsils, decrease in the size of the pre-pontine cistern, inferior displacement of the optic chiasm, effacement of perichiasmatic cisterns, crowding of the posterior fossa, pituitary enlargement, engorged venous sinuses and elongation of the brain stem in the anterior-posterior plane.

Spinal MRI performed in patients with PLPH demonstrates an extra-arachnoid or extradural fluid and dural venous sinus enhancement which might result in engorgement or prominence of the epidural venous plexus. Abnormal, intense, dural venous sinus enhancement indicates a compensatory venous expansion. Large epidural fluid collections extending anywhere from the cauda 
equina to the lower thoracic region can be seen in the MRI. These epidural fluid collections are capable of causing pressure on nerve roots, which is the most likely mechanism for the peripheral pain and numbness experienced by these patients [15-17].

\section{Factors Affecting PLPH}

The incidence of PLPH depends on patient-related and technique-related factors.

Some investigators conclude that PLPH is more common in young women with lower body mass index (BMI) and some did not find a correlation between BMI and the incidence of PLPH [18-21]. However, patients who suffered from previous PLPH are more likely to develop another PLPH following LP [22-26], and PLPH is less frequent in young children ( $<13$ years) and elderly adults ( $>60$ years) $[20]$

The amount of spinal fluid removed is not a risk factor for PLPH [21] and there is no evidence that increased fluid intake can prevent PLPH [26]. Evidence shows that regular needles with a sharp tip (Quincke) should be placed parallel to the long vertical axis of the patient's spine, in order to decrease the incidence of PLPH by up to $40 \%$ by limiting the damage to the dura associated with this technique $[21,23,27,28]$

Reinsertion of a stylet before needle withdrawal may facilitate dural closure by reinserting arachnoid particles into the dura, resulting in decreased CSF leakage $[29,30]$. The patient's position during LP and the duration of recumbence following LP did not influence the occurrence of headache [21], whereas, in contrast to widespread belief, immediate mobilization seems to be preferable after $\mathrm{LP}$, as described in 2 randomized controlled trials comparing a 4 - and 6-hour bed rest with immediate mobilization. Neither study found any difference in the incidence of PLPH. On the contrary, immediate ambulation seems to prevent some of the unwanted effects of LP, and significantly lowered frequency of nausea was shown for women $[19,31,32]$.

Spinal anesthesia and myelography differ from diagnostic LP; since smaller gauge $(G)$ needles are then used, smaller volumes of CSF fluid are drawn and a small volume of anesthetics and analgesics can be injected. The incidence of headache following spinal anesthesia is typically half of that seen with diagnostic LP. The needle size used for an LP is a significant determinant for PLPH [20, $33,34,35]$.
A recent study conducted in an emergency department compared the outcome after LP with traumatic 20and $22-\mathrm{G}$ needles and proved significant reduction in PLPH rates between 20- and 22-G Quincke needles [36].

The superiority of smaller atraumatic needles in decreasing the prevalence of PLPH was concluded by the report of the Therapeutics and Technology Assessment Subcommittee of the American Academy of Neurology. The committee concluded that diagnostic LP can be easily and accurately performed by using an atraumatic needle with the potential for considerable reduction in postLP headache and related neurologic sequels [37]. The committee based its conclusion on 1 prospective randomized trial that demonstrated that the use of an atraumatic Sprotte needle for LP reduces PLPH [38]. The atraumatic needle is easy to use and can significantly reduce the incidence of PLPH. A significant issue that is still under debate is whether CSF opening pressure measurement is practicable and accurate while a small needle is used as this determination increases the duration of the procedure significantly. 22-G atraumatic needles are reported to rapidly measure CSF pressure, but their flow rates were only suitable for a small volume of CSF collection and the failure rate was higher [39-44]. Our group recently published a controlled randomized trial comparing 22-G Quincke and atraumatic needles. We had no failed LPs and demonstrated a significant reduction in PLPH. However, we did not try to measure opening pressures in this study [45]. The cost of the atraumatic needle was reported a 7 -fold more expensive than standard needles [41]. The needle cost should be offset by the reduced need for medical intervention following LPs as was shown to be the case by us and others. Furthermore, the cost of atraumatic needles has decreased dramatically in the past 10 years, and currently the cost of a $22-G$ atraumatic needle is about twice that of a 22-G Quincke needle.

A survey about the use of different needles design for LP among US neurologists found that atraumatic needles are rarely used by members of specialties outside of anesthesiology. Only 2\% of neurologists surveyed in this 2001 publication routinely used atraumatic spinal needles. Almost half of the responding neurologists reported having no knowledge of atraumatic needles. Among those who were aware of these new spinal needles, the most common reasons given for not using them were nonavailability and expensive use. Although the application of these needles is standard practice among anesthesiologists, and despite the evidence for their superiority reported in the literature, the use of this needle has not been adopted by other medical specialties, which may lead to unneces- 
sary morbidity among patients undergoing LP [46]. This publication preceded the 2005 report of the Subcommittee of the American Academy of Neurology, and there are no data to follow on current practice.

\section{PLPH Treatment}

The conventional treatment is based on analgesics, increased fluids uptake, especially caffeine-containing beverages, and bed rest [47, 48].

Caffeine administered intravenously or orally is effective against PLPH since caffeine relieves PLPH by vasoconstriction of the dilated cerebral blood vessels, as evidenced by a global reduction in cerebral blood flow. A recent review aimed at evaluating the efficacy of caffeine treatment for reduction of the incidence and severity of PLPH, and concluded that based on the current stage of knowledge there is no scientific justification for the widely accepted caffeine treatment to prevent and treat PLPH found in textbooks and review articles since this practice is insufficiently supported by the available pharmacological and clinical evidence [49]. In spite of this publication, caffeine is still used empirically as a first-line approach for treating PLPH.

A blood patch can be offered when severe disabling pain does not respond to the conventional treatment. This procedure is described by anesthesiologists, mostly after accidental dural puncture with a Tuohy needle used for epidural anesthesia [50]. The placing of an epidural blood patch by an experienced care giver is highly successful with success rates for relief of PLPH between 56 and $98 \%$. An epidural tap is performed at the level of the prior LP. The loss-of-resistance technique using sterile saline can be employed to locate the epidural space, 10-20 $\mathrm{ml}$ of autologous blood is then drawn aseptically into a syringe and slowly injected (1-2 ml every $10 \mathrm{~s}$ ) into the epidural space at the site of the dural puncture. The injection is slowed or discontinued if back pain or paresthesias develop. The patient is kept supine for $1 \mathrm{~h}$ while receiving intravenous hydration. Relief usually occurs within $20-$ $30 \mathrm{~min}$ of the procedure. However, epidural patches are less likely to be effective if symptoms have been present for less than 24-48 h, or more than 2 weeks. Pain relief is firstly achieved due to a mechanical compression formed by the blood in the thecal space increasing the subarachnoid pressure, forcing CSF cranially and inhibiting the flow of CSF through the dura, a more prolonged therapeutic effect is attributed to the blood patch forming a gelatinous tamponade, hence stopping the CSF leak and providing elevation of the reduced CSF pressure [51]. Patch failures (15-20\%) are believed to be due to an incorrect diagnosis, improper needle placement, or injection of an inadequate quantity of blood, and therefore a second patch is often successful. Complications reported after an epidural blood patch include back stiffness (15\%), paresthesias, radicular pain, subdural hematoma, adhesive arachnoiditis, bacterial meningitis, deterioration of mental status, seizures, and transient bradycardia [52]. The procedure should be used in patients with refractory PLPH who fail to respond to conservative therapy and should be performed by clinicians trained in conducting this procedure; however, the effectiveness of a prophylactic blood patch is not established.

Lately, intravenous $200 \mathrm{mg}$ theophylline infusion over forty minutes was suggested for treatment of PLPH. Theophylline was found to be a rapid, minimally invasive, and effective treatment for PLPH. This treatment might be attempted in PLPH patients before invasive techniques are used. However, other randomized trials should be performed before an evidence-based practice of this drug can be suggested [53].

Intracranial subdural hematoma is a rare complication following LP, but could be lethal if undiagnosed in a timely manner. The same mechanism has been postulated for both PLPH and subdural hematoma [47]. The leakage of CSF from the dural hole causes reduction in CSF volume, which lowers first the intraspinal pressure, and, more dangerously, the intracranial pressure. This alteration in cerebrospinal dynamics results in a caudallydirected movement of the spinal cord and brain, which in turn stretches the pain-sensitive structures, dura, cranial nerves and bridging veins. Cerebral veins empty into dural sinuses that are adherent to the inner table of the skull. These veins form short trunks passing directly from the brain to the dura mater. Bridging veins take a straight course between these 2 points with no tortuosity to allow for any possible displacement of the brain. These bridging veins are extremely fragile and might rupture due to minimal trauma at their weakest point in the subdural space. Patients who develop PLPH unrelieved by conservative measures, and present a change in PLPH character from postural to non-postural intractable headache associated with retro-orbital and frontal pain, require careful follow-up for early diagnosis and management of possible subdural hematoma. Since both PLPH and subdural hematoma occur due to the same mechanism, it might be favorably to perform blood patch that not only can eliminate PLPH, but decrease the chance of developing subdural hematoma [47]. 
Another group of patients at increased risk for complications associated with LP are the hematologic patients, including patients undergoing hematopoietic stem cell transplantation and those receiving intrathecal therapy with methotrexate and corticosteroids which are prone to life-threatening complications following LP such as subdural hematoma [6], cerebellar infarction [54] and superior sagittal sinus thrombosis [55]. The occurrence of additional signs and symptoms following PLPH should alert the clinician to the presence of more prominent intracranial pathology $[3,56]$.

\section{Practical Recommendations}

The data appearing in the current literature imply that LP should be performed with the 22-G or smaller atraumatic needle. The technique is easy to learn, and is a sim- ple way to decrease PLPH and probably the risk of lifethreatening intracranial complications such as subdural hematoma following LP. Bed rest after LP is currently the common practice which was not proven so far to decrease the incidence of PLPH.

If PLPH does occur, then, first, conservative treatment should be tried with bed rest, analgesics and increased fluids intake, especially caffeine-containing beverages.

If the pain is severe and disabling, and does not respond to conservative treatment, a blood patch should be considered at least 24-48 $\mathrm{h}$ following the LP.

When a patient who was diagnosed with PLPH has a change in the pain character, or additional neurological manifestations appear, an urgent brain CT/head MRI should be performed to exclude rarer life-threatening intracranial complications.

\section{References}

-1 Strupp M, Schueler O, Straube A, Von Stuckrad-Barre S, Brandt T: 'Atraumatic' Sprotte needle reduces the incidence of post-lumbar puncture headaches. Neurology 2001;57: 2310-2312.

-2 Serpell MG, Rawal N: Headaches after diagnostic dural punctures. BMJ 2000;321:973974.

\3 Bienfait HP, Gijtenbeek JM, van den Bent MJ, de Bruin HG, Voogt PJ, Pillay M: Cerebral venous and sinus thrombosis with cerebrospinal fluid circulation block after the first methotrexate administration by lumbar puncture. Neuroradiology 2002;44:929-932.

4 Richer S, Ritacca D: Sixth nerve palsy after lumbar anesthesia. Optom Vis Sci 1989;66: 320-321.

5 Samdani A, Garonzik IM, Zahos P: Subdural hematoma after diagnostic lumbar puncture. Am J Emerg Med 2004;22:316-317.

$\checkmark 6$ Kannan K, Koh LP, Linn YC: Subdural hematoma in two hematopoietic stem cell transplant patients with post-dural puncture headache and initially normal CT brain scan. Ann Hematol 2002;81:540-542.

7 Gaucher DJ Jr, Perez JA Jr: Subdural hematoma following lumbar puncture. Arch Intern Med 2002;162:1904-1905.

$>8$ Turnbull DK, Shepherd DB: Post-dural puncture headache: pathogenesis, prevention and treatment. Br J Anaesth 2003;91: 718-729.

9 Vilming S, Kloster R: Post-lumbar puncture headache: clinical features and suggestions for diagnostic criteria. Cephalalgia 1997;17: $778-784$
10 Cosio F, Bermejo-Alvarez MA, Fervienza P Jimenez LJ, Castanon E, Diaz ML: Temporary trigeminal disorder as a result of pneumocephalus after subarachnoid block. Br J Anaesth 2003;91:430-432.

11 Niedermuller U, Trinka E, Bauer G: Abducens palsy after lumbar puncture. Clin Neurol Neurosurg 2002;104:61-63.

12 Kilickan L, Gurkan Y, Ozkarakas H: Permanent sensorineural hearing loss following spinal anesthesia. Acta Anaesthesiol Scand 2002;46:1155-1157.

13 Nakaya M, Morita I, Horiuchi M: Recurrent hearing loss after myelography treated with epidural blood patch. Auris Nasus Larynx 2005;32:399-401.

14 Francia A, Parisi P, Vitale AM, Esposito V Life-threatening intracranial hypotension after diagnostic lumbar puncture. Neurol Sci 2001;V22:385-389.

15 Atabaki S, Ochsenschlager D: Post-lumbar puncture headache and backache in pediatrics: a case series and demonstration of magnetic resonance imaging findings. Arch Pediatr Adolesc Med 1999;153:770-773.

16 Settipani N, Piccoli T, La Bella V, Piccoli F: Cerebral venous sinus expansion in postlumbar puncture headache. Funct Neurol 2004; 19:51-52.

17 Hannerz J, Ericson K, Bro Skejo HP: MR imaging with gadolinium in patients with and without post-lumbar puncture headache. Acta Radiol 1999;40:135-141.

18 Vilming ST, Schrader H, Monstad I: The significance of age, sex, and cerebrospinal fluid pressure in post-lumbar-puncture headache. Cephalalgia 1989;9:99-106.
19 Vilming ST, Schrader H, Monstad I: Postlumbar-puncture headache: the significance of body posture: a controlled study of $300 \mathrm{pa}-$ tients. Cephalalgia 1988;8:75-78.

20 Vilming S, Kloster R, Sandvik L: The importance of sex, age, needle size, height and body mass index in post-lumbar puncture headache. Cephalalgia 2001;21:738-743.

21 Kuntz KM, Kokmen E, Stevens JC, Miller P, Offord KP, Ho MM: Post-lumbar puncture headaches: experience in 501 consecutive procedures. Neurology 1992;42:1884-1887.

22 Amorim JA, Valença MM: Postdural puncture headache is a risk factor for new postdural puncture headache. Cephalalgia 2008;28: $5-8$

23 Lybecker H, Moller J, May O, Nielsen H: Incidence and prediction of postdural puncture headache: a prospective study of 1021 spinal anesthesias. Anesth Analg 1990;70: 389-394

$>24$ Seeberger MD, Kaufmann M, Staender S, Schneider M, Scheidegger D: Repeated dural punctures increase the incidence of postdural puncture headache. Anesth Analg 1996; 82:302-305.

25 Munnur U, Suresh MS: Backache, headache, and neurologic deficit after regional anesthesia. Anesthesiol Clin N Am 2003;21:7186.

26 Evans RW, Armon C, Frohman EM, Goodin DS: Assessment: prevention of post-lumbar puncture headaches: report of the Therapeutics and Technology Assessment Subcommittee of the American Academy of Neurology. Neurology 2000;55:909-914. 
-27 Tarkkila PJ, Heine H, Tervo RR: Comparison of Sprotte and Quincke needles with respect to post dural puncture headache and backache. Reg Anesth 1992;17:283-287.

-28 Richman JM, Joe EM, Cohen SR, et al: Bevel direction and postdural puncture headache: a meta-analysis. Neurologist 2006;12:224228.

-29 Strupp M, Brandt T: Should one reinsert the stylet during lumbar puncture? N Engl J Med 1997;336:1190.

-30 Deibel M, Jones J, Brown M: Best evidence topic report: reinsertion of the stylet before needle removal in diagnostic lumbar puncture. Emerg Med J 2005;22:46.

-31 Broadley SA, Fuller GN: Lumbar puncture needn't be a headache. BMJ 1997;315:13241325.

-32 Teece S, Crawford I: Towards evidence based emergency medicine: best BETs from the Manchester Royal Infirmary. Bed rest after lumbar puncture. Emerg Med J 2002;19: 432-433.

-33 Susan Lowery AO: Incidence of postdural puncture headache and backache following diagnostic/therapeutic lumbar puncture using a $22 \mathrm{G}$ cutting spinal needle, and after introduction of a $25 \mathrm{G}$ pencil point spinal needle. Paediatr Anaesth 2008;18:230-234.

>34 Aamodt A, Vedeler C: Complications after LP related to needle type: pencil-point versus Quincke. Acta Neurol Scand 2001;103:396398.

35 Davies JR: Headache after diagnostic lumbar puncture: smaller is better where needles are concerned BMJ 2001;322:993-994.

\36 Seupaul RA, Somerville GG, Viscusi C, Shepard AJ, Hauter WE: Prevalence of postdural puncture headache after ED performed lumbar puncture. Am J Emerg Med 2005;23:913-915
37 Armon C, Evans RW: Therapeutics, Technology Assessment Subcommittee of the American Academy of N. Addendum to assessment: Prevention of post-lumbar puncture headaches: report of the Therapeutics and Technology Assessment Subcommittee of the American Academy of Neurology. Neurology 2005;65:510-512.

38 Strupp M, Schueler O, Straube A, Von Stuckrad-Barre S, Brandt T: 'Atraumatic' Sprotte needle reduces the incidence of post-lumbar puncture headaches. Neurology 2001;57: 2310-2312.

39 Candido KD, Stevens RA: Post-dural puncture headache: pathophysiology, prevention and treatment. Best Pract Res Clin Anaesthesiol 2003;17:451-469.

40 Carson D, Serpell M: Choosing the best needle for diagnostic lumbar puncture. Neurology $1996 ; 47: 33-37$.

41 Thomas SR, Jamieson DR, Muir KW: Randomised controlled trial of atraumatic versus standard needles for diagnostic lumbar puncture BMJ 2000;321:986-990.

42 Kleyweg RP, Hertzberger LI, Carbaat PA Significant reduction in post-lumbar puncture headache using an atraumatic needle: a double-blind, controlled clinical trial. Cephalalgia 1998;18:635-637.

43 Zimet A: Encourage the use of noncutting needles for diagnostic lumbar punctures Anesth Analg 2003;97:303.

-44 Smeltzer JS: Headache after diagnostic lumbar puncture: using 20 gauge needle is blunderbuss technique. BMJ 2001;322:993.

45 Lavi R, Yernitzky D, Rowe JM, Weissman A Segal D, Avivi I: Standard vs. atraumatic Whitacre needle for diagnostic lumbar puncture: a randomized trial. Neurology 2006;67:1492-1494.

-46 Birnbach DJ, Kuroda MM, Sternman D, Thys DM: Use of atraumatic spinal needles among neurologists in the United States. Headache 2001;41:385-390.

-47 Zeidan A, Farhat O, Maaliki H, Baraka A: Does postdural puncture headache left untreated lead to subdural hematoma? Case report and review of the literature. Int J Obstet Anesth 2006;15:50-58.
48 Harrington BE: Postdural puncture headache and the development of the epidural blood patch. Reg Anesth Pain Med 2004;29: 136-163.

49 Halker RB, Demaerschalk BM, Wellik KE, Wingerchuk DM, Rubin DI, Crum BA, Dodick DW: Caffeine for the prevention and treatment of postdural puncture headache: debunking the myth. Neurologist 2007;13: 323-327.

50 Williams EJ, Beaulieu P, Jenkins WJ: Efficacy of epidural blood patch in the obstetric population. Int J Obstet Anesth 1999;8:105109.

51 van Kooten F, Oedit R, Bakker SLM, Dippel DWJ: Epidural blood patch in post dural puncture headache: a randomised, observerblind, controlled clinical trial. J Neurol Neurosurg Psychiatry 2008;79:553-558.

52 Banks S, Paech M, Gurrin L: An audit of epidural blood patch after accidental dural puncture with a Tuohy needle in obstetric patients. Int J Obstet Anesth 2001;10:172176.

53 Ergün U, Say B, Ozer G, et al: Intravenous theophylline decreases post-dural puncture headaches. J Clin Neurosci 2008;15:11021104.

54 Nicol GLJ, Millns JP: Cerebellar infarction as a cause of post-partum headache. Int J Obstet Anesth 2002;11:306-309.

55 Mouraux A, Gille M, Dorban S, Peeters A: Cortical venous thrombosis after lumbar puncture. J Neurol 2002;249:1313-1315.

>56 Benzon HT, Iqbal M, Tallman MS, Boehlke L, Russell EJ: Superior sagittal sinus thrombosis in a patient with postdural puncture headache. Reg Anesth Pain Med 2003;28: 64-67. 